\title{
Salinity, osmolality, and zinc uptake in Palaemon elegans (Crustacea: Decapoda)
}

\author{
D. Nugegoda, P. S. Rainbow \\ Centre for Research in Aquatic Biology, School of Biological Sciences, Queen Mary College, Mile End Road, London E1 4NS, \\ England
}

\begin{abstract}
Rates of zinc uptake by the decapod crustacean Palaemon elegans Rathke at both $316 \mu \mathrm{g}$ $\mathrm{Zn} \mathrm{l}^{-1}$ and $120 \mu \mathrm{g} \mathrm{Znl^{-1 }}$ depend on changes in salinity but are independent of changes in osmolality. Zinc uptake rate increases with a decrease in salinity while osmolality is held constant, but does not change if osmolality is changed while salinity is held constant. Results are consistent with the view that the bioavailability of zinc depends on the concentration of the uncomplexed free metal ion.
\end{abstract}

\section{INTRODUCTION}

The decapod crustacean Palaemon elegans Rathke regulates its body concentration of zinc to a constant level over a wide range of ambient dissolved zinc, until a threshold zinc exposure when regulation breaks down and net accumulation of body zinc begins (White \& Rainbow 1982, 1984a). Rate of zinc uptake by the prawn increases with raised zinc bioavailability until, at the point of regulation breakdown, it exceeds the maximum rate of zinc excretion under ambient physicochemical conditions (White \& Rainbow 1984a, Nugegoda \& Rainbow 1987, 1988, 1989).

Reductions in salinity from $100 \%$ seawater (SW) to $50 \%$ SW cause an increase in zinc uptake by Palaemon elegans and correspondingly the dissolved zinc concentration at which zinc regulation breaks down decreases as salinity is reduced over this range (Nugegoda \& Rainbow 1989). In $25 \%$ SW however, in spite of increasing zinc uptake, there is no evidence of breakdown in body zinc regulation with increasing dissolved zinc exposure (Nugegoda \& Rainbow 1989).

Palaemon elegans shows a clear pattern of hyper/ hypo-osmoregulation with change in salinity of the medium (Panikkar 1941, Ramirez de Isla Hernandez \& Taylor 1985). The haemolymph of $P$. elegans from the Firth of Clyde, Scotland, has an isosmotic point at $10^{\circ} \mathrm{C}$ of ca 26 ppt $\mathrm{NaCl}$ (ca $80 \% \mathrm{SW}$ ) (Ramirez de Isla Hernandez \& Taylor 1985), and in more dilute media water tends to enter the prawn. Palaemonid prawns typically osmoregulate by increasing the efflux of water at low salinities, but since they produce a urine isosmotic to the blood and there is relatively little salt reabsorption in the excretory organs (antennary glands), much salt is lost at the same time (Panikkar 1941, Parry 1955, Mantel \& Farmer 1983). The increased osmotic water throughput and the consequent high rate of urine production by $P$, elegans at $25 \%$ SW may therefore allow an atypically high rate of zinc excretion, able to match the observed high rate of zinc uptake (Nugegoda \& Rainbow 1989).

This study investigates the effect on zinc uptake by Palaemon elegans of a change in salinity in a medium of constant osmolality, whereas in earlier experiments (Nugegoda \& Rainbow 1989) the osmolality of experimental media decreased in proportion with salinity. Salinity depends only on the inorganic content of seawater, whereas osmolality ultimately depends on the total number of particles in solution, whether inorganic or organic. The osmolality of a solution of constant salinity therefore can be altered by the addition of an organic molecule, and sucrose is used to this end in the experiments described here.

\section{MATERIALS AND METHODS}

Palaemon elegans Rathke were collected from littoral rockpools near Millport, Isle of Cumbrae, Firth of Clyde, Scotland, and maintained in the laboratory for at least 1 wk before use at $10^{\circ} \mathrm{C}$ and $32 \mathrm{ppt}$ salinity (TMN, Tropicarium Buchschlag Dreieich, F. R. Germany).

The osmolality of TMN of 32 ppt salinity (100\% SW) 
was measured to be $924 \pm 17 \mathrm{mOsm} \mathrm{kg}^{-1}$ (Advanced Instruments Inc. Laboratory Osmometer, model 3L). The osmometer was calibrated daily with $\mathrm{NaCl}$ standards. Appropriate volumes of a sucrose solution made isosmotic with $100 \%$ SW (ca 0.84 molal sucrose solution; Weast 1977) were used to maintain the osmolality of diluted TMN when the salinity was reduced. The mean zinc concentration of this isosmotic sucrose solution was $22 \pm 6 \mu \mathrm{g} \mathrm{l}^{-1}$. This zinc concentration was taken into account when dosing experimental media with extra, zinc although it could not be assumed that the zinc contributed from the sucrose would be bioavailable to the same degree as added inorganic zinc.

Initial experiments showed that Palaemon elegans could not survive more than $3 \mathrm{~d}$ in $25 \%$ SW made isosmotic with $100 \%$ SW using the isosmotic sucrose solution. There was however less than $3 \%$ mortality of prawns in $25 \%$ SW made isosmotic with $75 \%$ SW, and the latter medium was used to change the osmolality while maintaining the salinity constant.

All experiments were carried out in acid-washed Perspex tanks at $10^{\circ} \mathrm{C} \pm 0.5 \mathrm{C}^{\circ}$ under a $12: 12 \mathrm{~h}$ light: dark regime with continuous aeration. Prawns were always held individually in compartmented Perspex boxes. Prawns were fed as indicated below for $15 \mathrm{~min}$ with lamb's heart ( $\left.77 \mu \mathrm{g} \mathrm{Zn} \mathrm{g}^{-1}\right)$, a negligible dietary source of zinc, in separate feeding tanks in clean TMN of appropriate salinity and osmolality.

For zinc analysis, prawns were individually frozen before being thawed, dried to constant weight at $60^{\circ} \mathrm{C}$ and digested in conc $\mathrm{HNO}_{3}$ (Aristar grade, BDH Ltd.) at $100^{\circ} \mathrm{C}$. Digests were made up to volume with double distilled water and analyzed for total Zn by AAS (Varian AA 375 spectrophotometer with background correction) and/or analyzed for Zn-65 activity in a Nuclear Chicago 1185 gamma scintillation counter against standards of the same sample geometry. When the prawns were monitored for Zn-65 activity the method of White \& Rainbow (1984a) was used, all live counts being corrected against counts of the final acid digest of each prawn.

\section{EXPERIMENTAL DETAILS}

\section{Experiment 1: Zn uptake and loss by Palaemon elegans in solutions of the same salinity but different osmolality with $316 \mu \mathrm{g} \mathrm{Zn} \mathrm{l}^{-1}$}

TMN of 32 ppt salinity, isosmotic sucrose solution and distilled water were used to prepare Tank $X$ with $25 \%$ SW isosmotic to $75 \%$ SW, and Tank Y with $25 \%$ SW alone. Each tank was dosed with $316 \mathrm{~kg} \mathrm{l}^{-1}$ total zinc labelled with $4 \mu \mathrm{Ci} \mathrm{I}^{-1} \mathrm{Zn}-65$ (after accounting for zinc contributed by sucrose in Tank $X$ and by TMN in all tanks).

Ten prawns were acclimated to $25 \%$ SW for $3 \mathrm{~d}$ before being placed in either Tank X or Tank $Y$ for $7 \mathrm{~d}$. Experimental media were changed on Day 3. Labelled zinc in individual prawns was monitored by live counting after $8,23,31,46,55,72$ and $96 \mathrm{~h} ; 5,6$, and $7 \mathrm{~d}$. Prawns from Tank $X$ were then transferred for $14 \mathrm{~d}$ into Tank $X_{1}$, and those from $Y$ into Tank $Y_{1} ; X_{1}$ and $Y_{1}$ being identical to $X$ and $Y$ respectively but without labelled zinc in the total $316 \mu \mathrm{g} \mathrm{Zn}{ }^{-1}$ (media changed every 3rd day). Labelled zinc in individual prawns in Tanks $X_{1}$ and $Y_{1}$ was monitored after $0.25,1,2,3,5,7$. 9,12 and $14 \mathrm{~d}$. Prawns were fed every other day and at the end of the experiment each prawn was frozen individually for analysis for total and labelled zinc.

Eight initial prawns acclimated to $25 \%$ SW for $3 \mathrm{~d}$ were taken at the start of the experiment. Two control tanks without added zinc, one with $25 \%$ SW isosmotic to $75 \%$ SW and the other with $25 \%$ SW, with 8 acclimated prawns in each, were maintained for $21 \mathrm{~d}$. The media were replaced every 5 th day. Control and initial prawns were analysed for total zinc.

Experiment 2: Zn uptake and loss by Palaemon elegans in solutions of (i) same salinity but different osmolality, (ii) same osmolality but different salinity, with $120 \mu \mathrm{g} \mathrm{Zn} \mathrm{l^{-1 }}$

Four tanks were prepared with (A) $25 \%$ SW isosmotic to $75 \% \mathrm{SW}$, (B) $25 \% \mathrm{SW}$, (C) $75 \% \mathrm{SW}$ and (D) $75 \%$ SW (again). Labelled zinc was added to give a final concentration of $120 \mu \mathrm{g} \mathrm{Zn} \mathrm{l^{-1 }}$ in each tank.

Ten Palaemon elegans, acclimated to $25 \% \mathrm{SW}$ for $3 \mathrm{~d}$, were placed in each of Tanks $\mathrm{A}$ and $\mathrm{B} ; 10 P$. elegans acclimated to $75 \% \mathrm{SW}$ for $3 \mathrm{~d}$, were placed in each of Tanks $C$ and D. Tanks were held for $7 d$, media being replaced after $3 \mathrm{~d}$.

After $7 \mathrm{~d}$, prawns from Tank A were placed in Tank $\mathrm{A}_{1}$, with the same medium as $\mathrm{A}$ (i.e. $25 \% \mathrm{SW}$ isosmotic with $75 \%$ SW) with no added zinc. Prawns from Tanks $B, C$ and $D$ were similarly placed in Tanks $B_{1}, C_{1}$ and $D_{1}$ respectively. Tanks $B_{1}$ and $C_{1}$ had the same media as $B$ and $C$ (i.e. $25 \%$ SW and $75 \%$ SW respectively) while $D_{1}$ also had $25 \%$ SW. Cold zinc was added to Tanks $B_{1}$, $C_{1}$ and $D_{1}$ to achieve a total concentration of $10.6 \mu \mathrm{g} \mathrm{Zn}$ $1^{-1}$ which was equal to the zinc concentration in $A_{1}$ (unavoidable contribution from the isosmotic sucrose and TMN\}. Tanks $A_{1}, B_{1}, C_{1}$ and $D_{1}$ were held for $11 \mathrm{~d}$, the media being replaced every $3 \mathrm{rd}$ day. The labelled zinc in each prawn was monitored after $8,23,31,46,54$ and $72 \mathrm{~h} ; 4,5$ and $7 \mathrm{~d}$ in the labelled zinc phase; and 5 , $22,45,93 \mathrm{~h} ; 7,9$ and $11 \mathrm{~d}$ in the non-labelled zinc phase. Prawns were fed at the start of the experiment, 
after $31 \mathrm{~h}$, and then every other day. Finally prawns were frozen individually for analysis for total and labelled zinc.

Eight prawns acclimated to $25 \%$ SW and 8 prawns acclimated to $75 \%$ SW were frozen as initials at the start of the experiment. Three control tanks with $25 \%$ SW isosmotic to $75 \%$ SW, $25 \%$ SW and $75 \%$ SW respectively with 8 individually held prawns in each, were also held for $18 \mathrm{~d}$ and fed similarly. The media in control tanks were replaced every 5 th day. Initial and control prawns were frozen for analysis for total zinc.

Statistical comparisons were made using analysis of variance (Sokal \& Rohlf 1981), usually after log transformation of the data. All metal concentrations of prawns are in $\mu \mathrm{g} \mathrm{g}^{-1}$ dry weight.

\section{RESULTS}

Monitoring of dissolved labelled zinc concentrations in both experiments confirmed that concentrations remained within $7 \%$ of declared values. Concen-

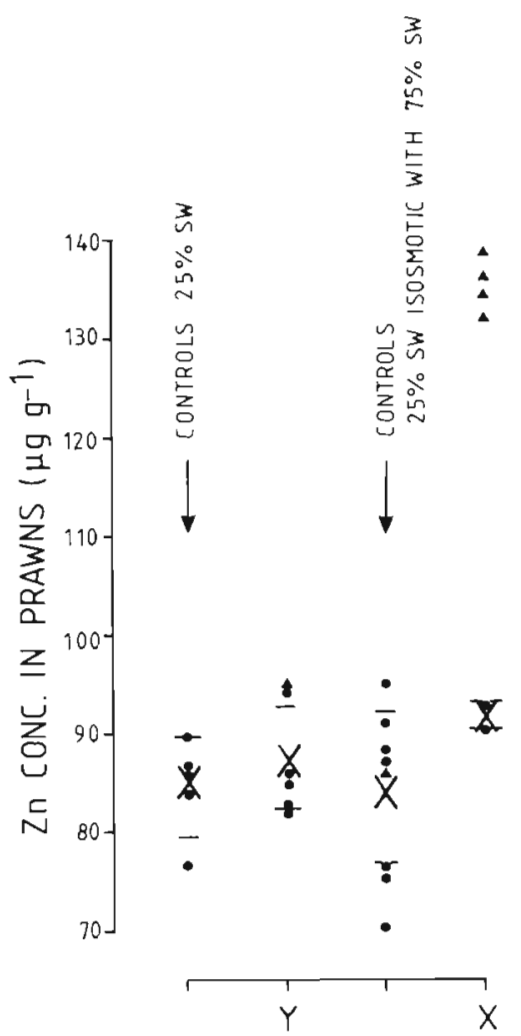

Fig. 1. Palaemon elegans. Total body zinc concentrations in prawns surviving exposure to $316 \mu \mathrm{g} \mathrm{l}^{-1}$ labelled zinc for $7 \mathrm{~d}$, followed by exposure to $316 \mu \mathrm{g} \mathrm{l}^{-1}$ unlabelled zinc for a further $14 \mathrm{~d}$ at $10^{\circ} \mathrm{C}$ in Tanks X (25\% SW isosmotic to $\left.75 \% \mathrm{SW}\right)$ and $\mathrm{Y}$ $(25 \% \mathrm{SW})$, and in 2 control tanks (Experiment 1 - see text). $\Delta$ : prawns moulted before Day 19; $\bullet$ non-moulters; $X$ : mean zinc concentrations in surviving non-moulters in each exposure; -: $\pm 1 \mathrm{SD}$ on either side of the mean trations of dissolved labelled zinc during non-labelled phases of all experiments were negligible, confirming that in all cases recycling of labelled zinc was also negligible.

\section{Experiment 1: Zn uptake and loss under constant salinity but varying osmolality}

Fig. 1 gives the mean total body zinc concentrations of control and experimental prawns in Experiment 1. The zinc concentrations of the 2 non-moulting prawns held in $25 \% \mathrm{SW}$ isosmotic to $75 \% \mathrm{SW}$ (Tank X) were higher than the mean zinc concentration in any of the other groups. These mean zinc concentrations in all other groups were not significantly different from each other, nor from the mean zinc concentrations in initial prawns. It may be the case that the regulation of body zinc concentrations by prawns has broken down in prawns from Tank $X$ but lack of numbers of nonmoulters prevents this being concluded with certainty. Regulation had not broken down in the other 3 tanks.

In line with earlier observations (White \& Rainbow 1984a, b, Nugegoda \& Rainbow 1988, 1989), prawns in Tank $X$ that moulted during the experiment had further elevated total body zinc concentrations. All prawns moulting when exposed to zinc in Tank $X$ survived but the 2 prawns that moulted in Tank Y died. There was $40 \%$ mortality in both osmolality regimes.

The rates of uptake of labelled zinc of individual Palaemon elegans were estimated by fitting asymptotic curves $\left(Z_{t}=Z_{s s}-Z_{a} e^{-k t}\right)$ to the data for the accumulation of labelled zinc up to $3 d$, as described by Nugegoda \& Rainbow (1988) (see Fig. 2). The rates of zinc uptake by the prawns in $25 \% \mathrm{SW}$ isosmotic to $75 \%$ SW (Tank X) and in $25 \%$ SW (Tank Y) are shown in Table 1. There was no significant difference ( $p$ $>0.75$ ) between the mean rates of zinc uptake of prawns from Tanks X and Y. It can therefore be concluded that there was no change in the zinc uptake rate of $P$. elegans when the salinity was held constant and the osmolality changed. Also identified in the table are individual prawns that subsequently moulted or died, with consequent omission from later analyses of total zinc concentration or rate of loss of labelled zinc according to time of death or moult.

Figs. 3 and 4 show the loss of labelled zinc by individual prawns from each osmolality regime after transfer from labelled to unlabelled media at the same $\mathrm{Zn}$ concentration of $316 \mu \mathrm{g} \mathrm{l}^{-1}$. The results showed an initial immediate loss of labelled zinc over the first day (Figs. 3 and 4), interpreted as surface exchange of labelled zinc with unlabelled zinc in the medium (Fig. 5). Therefore the zero hour datum point has been left out of analyses estimating the rate of loss of labelled 

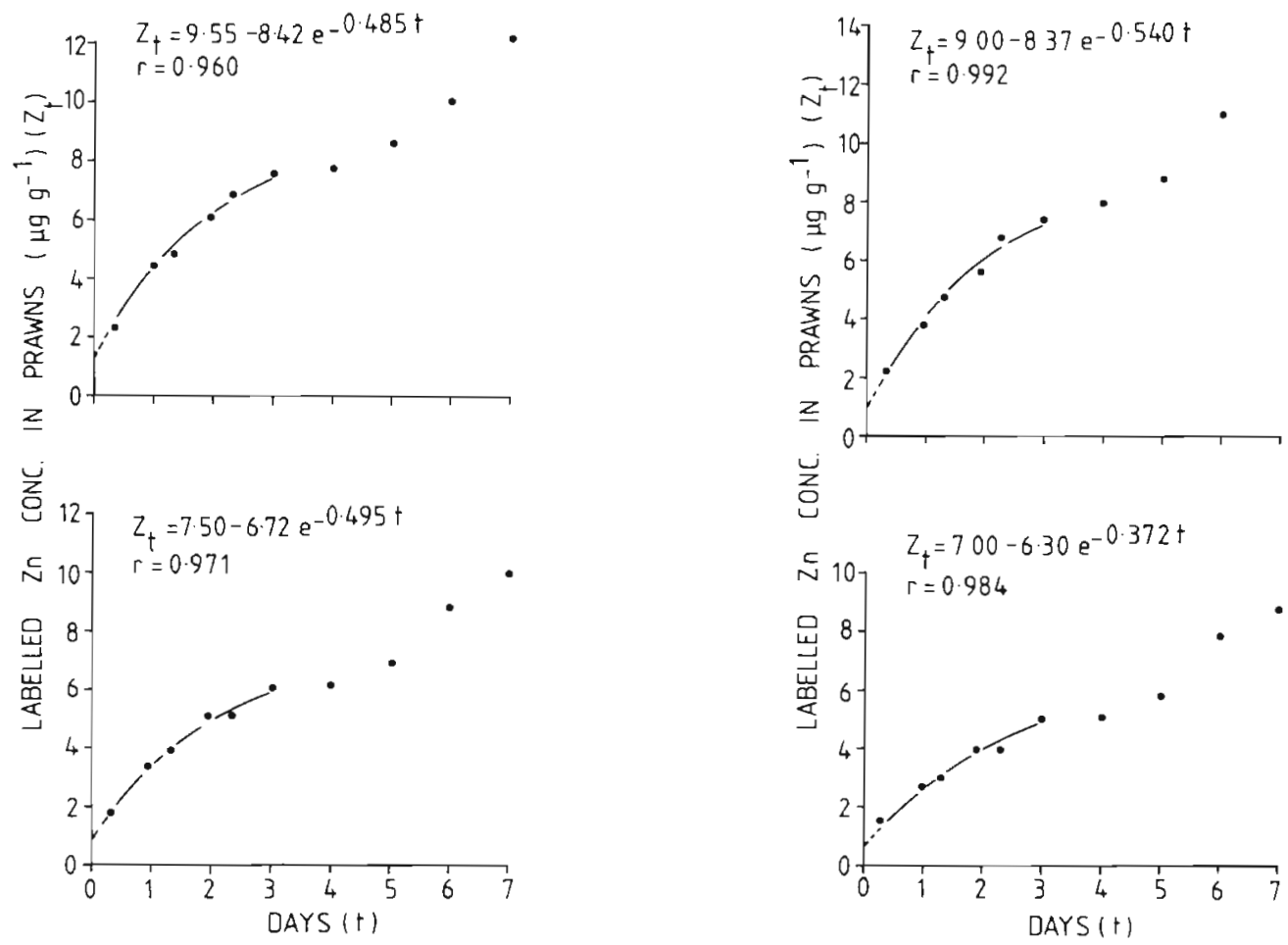

Fig. 2. Palaemon elegans. Accumulation of labelled zinc $\left(\mu \mathrm{g} \mathrm{g}^{-1}\right)$ by 2 individual prawns exposed to $316 \mu g l^{-1}$ labelled zinc in $25 \% \mathrm{SW}$ isosmotic to $75 \% \mathrm{SW}$ (Tank X) (left), and in $25 \% \mathrm{SW}$ (Tank Y) (right), both at $10^{\circ} \mathrm{C}$ for $7 \mathrm{~d}$. Asymptotic curves were fitted to data up to $3 \mathrm{~d}(p<0.01)$, using the equation $Z_{t}=Z_{s s}-Z_{a} e^{-k i} ;$ where $Z_{t}=$ concentration of labelled $Z n$ in prawns at time $t_{1} Z_{s s}=$ concentration of labelled $\mathrm{Zn}$ in prawns at steady state after subtraction of labelled $\mathrm{Zn}$ concentration initially adsorbed $\left(Z_{a}\right)$

Table 1. Palaemon elegans. Rates of zinc uptake $\left(\mu \mathrm{g} \mathrm{\textrm {g } ^ { - 1 }} \mathrm{d}^{-1}\right)$ by individual prawns in $25 \% \mathrm{SW}$ isosmotic to $75 \% \mathrm{SW}$ (Tank $\mathrm{X}$ ) and in $25 \%$ (Tank Y), each with $316 \mu \mathrm{g} \mathrm{Zn} \mathrm{l}^{-1}$ at $10^{\circ} \mathrm{C} . \mathrm{m}=$ prawn subsequently moulted; $\mathbf{d}=$ prawn subsequently died

\begin{tabular}{|lll|}
\hline & Tank X & Tank Y \\
\hline & 3.33 & 2.34 \\
& $3.83 \mathrm{~d}$ & 3.13 \\
& $4.03 \mathrm{~d}$ & 4.52 \\
& 4.08 & 5.22 \\
& $5.33 \mathrm{~m}$ & $6.64 \mathrm{~m}$ \\
& $6.36 \mathrm{~m}$ & 8.46 \\
& $8.18 \mathrm{~d}$ & $9.40 \mathrm{~d}$ \\
& $9.36 \mathrm{~d}$ & $9.82 \mathrm{~m}, \mathrm{~d}$ \\
& $9.96 \mathrm{~m}$ & $10.13 \mathrm{~d}$ \\
Mean & $10.25 \mathrm{~m}$ & \\
SD & 6.47 & 6.63 \\
$n$ & 2.74 & 2.97 \\
\hline
\end{tabular}

zinc from the body. The data for the labelled zinc in prawns for 1 to $14 \mathrm{~d}$ in unlabelled media could be fitted adequately to a simple exponential loss curve $\mathrm{Zt}=$ $\mathrm{Ce}^{-\mathrm{kt}}$ (Fig. 5).

The rate of loss of labelled zinc can be calculated from the equation at any point on the curve as

$$
\frac{d Z_{t}}{d t}=(-k) C e^{-k t}
$$

At $t=0$, the initial rate of loss of labelled zinc is therefore

$$
\frac{\mathrm{d} \mathrm{Z}_{\mathrm{t}}}{\mathrm{dt}}=(-\mathrm{k}) \mathrm{C} \text {. }
$$

Table 2 compares rates of loss of labelled zinc in prawns from Tanks $X_{1}$ and $Y_{1}$ in Experiment 1. There is an indication that the loss of labelled zinc is greater in $25 \%$ SW than in $25 \%$ isosmotic to $75 \%$ seawater, but analysis of variance showed no significant difference $(p>0.05)$, given the low number of data points and the high variability.

In both media the rates of loss of labelled zinc from prawns after transfer into unlabelled zinc were less than the measured rates of uptake of zinc by prawns before transfer.

\section{Experiment 2: Zn uptake and loss under variable conditions of salinity and osmolality}

Table 3 lists the mean total zinc concentrations of prawns from Experiment 2. There was no significant difference between the mean $\mathrm{Zn}$ concentrations of 


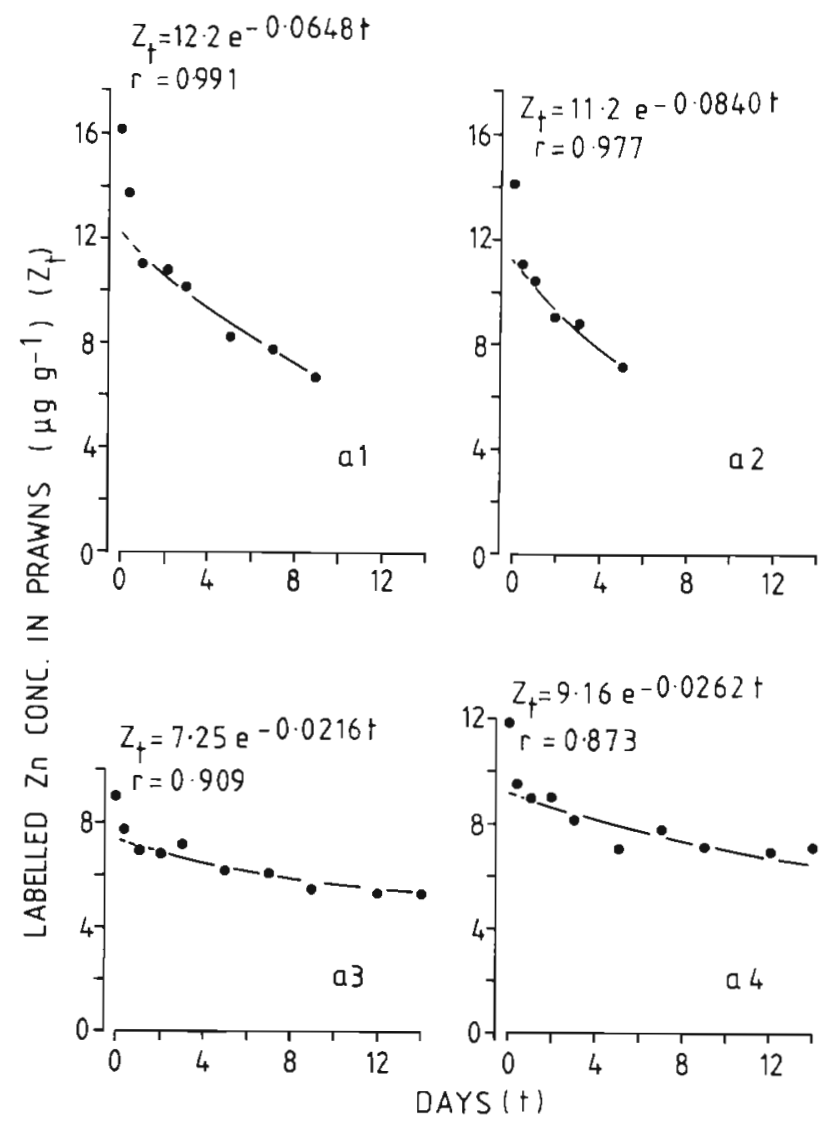

Fig. 3. Palaemon elegans. Loss of labelled zinc from individual prawns $\left(\mu \mathrm{g} \mathrm{g}^{-1}\right)$ in $25 \% \mathrm{SW}$ isosmotic to $75 \%$ SW (Tank $\left.\mathrm{X}_{1}\right)$ with $316 \mu \mathrm{g} \mathrm{l}^{-1}$ unlabelled zinc over $14 \mathrm{~d}$ at $10^{\circ} \mathrm{C}$, following exposure to $316 \mu \mathrm{g} \mathrm{l}^{-1}$ labelled zinc for $7 \mathrm{~d}$. Fitted exponential loss curves are significant at $p<0.05$. Last datum point for each prawn is at the end of the experiment (Day 21) or for the point at which the prawn died. $a_{1}$ to $a_{4}$ identifies individual prawns

prawns in any of the groups. It is concluded that Palaemon elegans regulated body zinc concentrations in all exposure regimes.

The rates of zinc uptake of individual Palaemon elegans exposed to $120 \mu \mathrm{g} \mathrm{Zn} \mathrm{l}^{-1}$ in Tanks A, B, C and $\mathrm{D}$ are shown in Table 4, estimated using data for the accumulation of labelled zinc up to Day 7. There is great individual variability in zinc uptake rates of Palaemon elegans even within the same exposure regime. A posteriori analysis of variance showed that the mean rate of zinc uptake of prawns in Tanks $A$ and B (both with $25 \%$ SW, A isosmotic to $75 \%$ SW) were not significantly different from each other. Similarly the mean rates of zinc uptake of prawns in Tanks C and D (both with $75 \% \mathrm{SW}$ ) were not significantly different from each other. However the mean rates of zinc uptake in Tanks $A$ and $B$ were significantly higher than in Tanks $C$ and D.

The rate of zinc uptake in Palaemon elegans there-
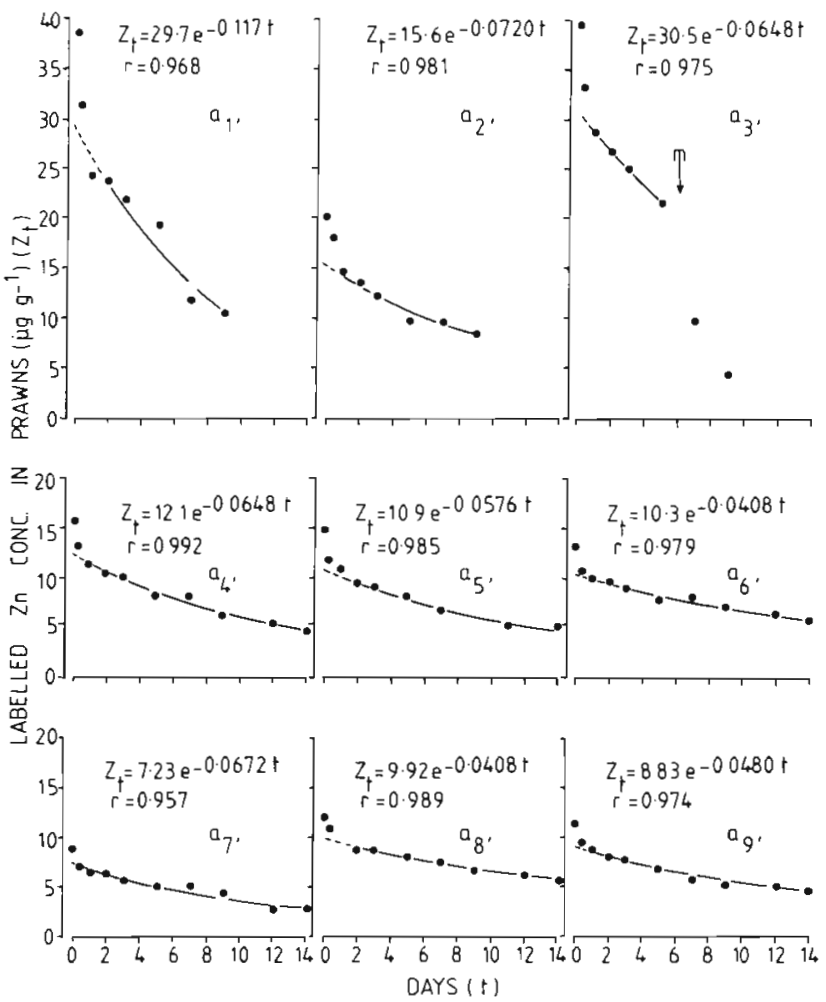

Fig. 4. Palaemon elegans. Loss of labelled zinc from individual prawns $\left(\mu \mathrm{g} \mathrm{g}^{-1}\right)$ in $25 \% \mathrm{SW}$ (Tank $\mathrm{Y}_{1}$ ) with $316 \mu \mathrm{g}$ unlabelled zinc $l^{-1}$ over $14 \mathrm{~d}$ at $10^{\circ} \mathrm{C}$, following exposure to $316 \mu \mathrm{g} \mathrm{l}^{-1}$ labelled zinc for $7 \mathrm{~d}$. Fitted exponential loss curves are significant at $p<0.05 . \mathrm{m}=$ prawn moulted. Last datum point for each prawn is at the end of experiment (Day 21) or for the point at which the prawn died. $a_{1}$. to $a_{9}$, identifies individual prawns

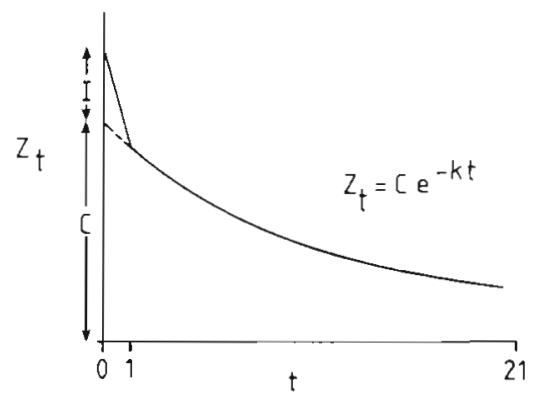

Fig. 5. Palaemon elegans. Theoretical curve for the loss of labelled zinc from individual prawns. $I=$ the initial loss of labelled zinc $\left(\mu \mathrm{g} \mathrm{g}^{-1}\right)$ interpreted to be a result of surface exchange; $Z_{t}=$ labelled zinc concentration in prawn $\left(\mathrm{kg} \mathrm{g}^{-1}\right)$ at time $\mathrm{t}$ (days); $\mathrm{C}=$ labelled zinc concentration in prawn (excluding the labelled zinc lost as a result of initial surface exchange) at time $t=0 ; k=$ the rate constant in terms of the fraction of the pool of zinc moving per unit time

fore increases with a decrease in salinity as seen in Experiment 1. The results of both experiments provide evidence that this increase in zinc uptake is not an effect of decrease in osmolality of the medium. The mean zinc uptake rate of prawns in this experiment 
Table 2. Palaemon elegans. Rates of labelled zinc loss $\left(\mu \mathrm{g} \mathrm{g}^{-\mathrm{i}}\right.$ $\left.\mathrm{d}^{-1}\right)$ by individual prawns in Tanks $\mathrm{X}_{1}(25 \% \mathrm{SW}$ isosmotic to $75 \% \mathrm{SW})$ and $Y_{1}(25 \% \mathrm{SW})$, with $316 \mu \mathrm{g} \mathrm{l^{-1 }}$ unlabelled zinc, following $7 \mathrm{~d}$ uptake in $316 \mu \mathrm{g} \mathrm{I}^{-1}$ of labelled zinc, at $10^{\circ} \mathrm{C}$. $\mathrm{m}=$ prawn subsequently moulted, $\mathrm{d}=$ prawn subsequently died

\begin{tabular}{lll|}
\hline & Tank $X_{1}$ & Tank $Y_{1}$ \\
\hline & 0.16 & 0.40 \\
& 0.24 & $0.42 \mathrm{~m}$ \\
& $0.79 \mathrm{~d}$ & 0.42 \\
& 0.94 & 0.49 \\
& & 0.63 \\
& & 0.79 \\
& & $1.12 \mathrm{~d}$ \\
& & $3.98 \mathrm{~m}, \mathrm{~d}$ \\
Mean & 0.53 & 1.08 \\
SD & 0.39 & 1.03 \\
$n$ & 4 & 9 \\
\hline
\end{tabular}

with $120 \mu \mathrm{g} \mathrm{Zn} \mathrm{l^{-1 }}$ was significantly lower than in the first experiment with $316 \mu \mathrm{g} \mathrm{Zn} \mathrm{I}^{-1}$, both in $25 \% \mathrm{SW}$ and in $25 \% \mathrm{SW}$ isosmotic to $75 \% \mathrm{SW}$

The losses of labelled zinc by individual prawns in Tanks $A_{1}, B_{1}, C_{1}$ and $D_{1}$ with $25 \%$ SW isosmotic to $75 \%$ SW, $25 \%$ SW, $75 \%$ SW and $75 \%$ SW (after uptake in $75 \% \mathrm{SW}$ ) respectively, each with $10.6 \mu \mathrm{g} \mathrm{Zn} l^{-1}$, were fitted to the exponential loss curve. The calculated rates of labelled zinc loss are presented in Table 5. These rates in all cases are less than the rates of zinc uptake prior to transfer of prawns to unlabelled media. The mean rate of loss of labelled zinc (Table 5) from prawns in $25 \% \mathrm{SW}$ isosmotic to $75 \% \mathrm{SW}$ (Tank $\mathrm{A}_{1}$ ) appears to be lower than the mean rate of loss of labelled zinc from prawns in $25 \%$ SW (Tank $B_{1}$ ), although mean uptake rates during the labelled uptake phase had not been significantly different (Table 4). However, as in Experiment 1, analysis of variance

Table 3. Palaemon elegans. Mean total zinc concentrations in initial prawns and in control and experimental prawns $\left(\mu \mathrm{g} \mathrm{g}^{-1} \pm 1\right.$ $\mathrm{SD}$ ) after $18 \mathrm{~d}$ exposure to the stated salinity-osmolality regime, where experimental prawns were exposed to a nominal labelled zinc concentration of $120 \mu \mathrm{g} \mathrm{l}^{-1}$ in the uptake phase $(7 \mathrm{~d})$ and $10.6 \mu \mathrm{g} \mathrm{l}^{-1}$ unlabelled zinc in the loss phase $(11 \mathrm{~d})$ at $10^{\circ} \mathrm{C}$. $\mathrm{n}=$ number of samples

\begin{tabular}{|c|c|c|c|}
\hline Salinity-osmolality regime & $\begin{array}{l}\text { Initial } \\
(n)\end{array}$ & $\begin{array}{l}\text { Control } \\
(n)\end{array}$ & $\begin{array}{l}\text { Experimental } \\
\qquad(n)\end{array}$ \\
\hline $\begin{array}{l}25 \% \mathrm{SW} \text { isosmotic } \\
\text { to } 75 \% \mathrm{SW}\end{array}$ & - & $81.4 \pm 6.5$ & $79.4 \underset{(7)}{ \pm} 11.2$ \\
\hline $25 \%$ SW & $\begin{array}{c}88.2 \pm 6.4 \\
(8)\end{array}$ & $\begin{array}{c}84.8 \pm 4.2 \\
(5)\end{array}$ & $85.9 \pm 11.8$ \\
\hline $75 \% \mathrm{SW}$ & $86.1 \pm 9.2$ & $83.1 \pm 6.2$ & $\begin{array}{c}85.4 \pm 12.0 \\
(10)\end{array}$ \\
\hline $\begin{array}{l}\text { Uptake in } 75 \% \mathrm{SW} \text {, } \\
\text { loss in } 25 \% \mathrm{SW}\end{array}$ & - & - & $\begin{array}{c}85.5 \pm 8.4 \\
(7)\end{array}$ \\
\hline
\end{tabular}

Table 4. Palaemon elegans. Rates of zinc uptake (ug g $\left.\mathrm{g}^{-1} \mathrm{~d}^{-1}\right)$ by individual prawns in A ( $25 \%$ isosmotic to $75 \%$ SW) B (25 $\%$ SW) C and D (75\% SW) with $120 \mu \mathrm{g} \mathrm{I}^{-1}$ labelled zinc at $10^{\circ} \mathrm{C} . \mathrm{m}=$ prawn subsequently moulted, $\mathrm{d}=$ prawn subsequently died

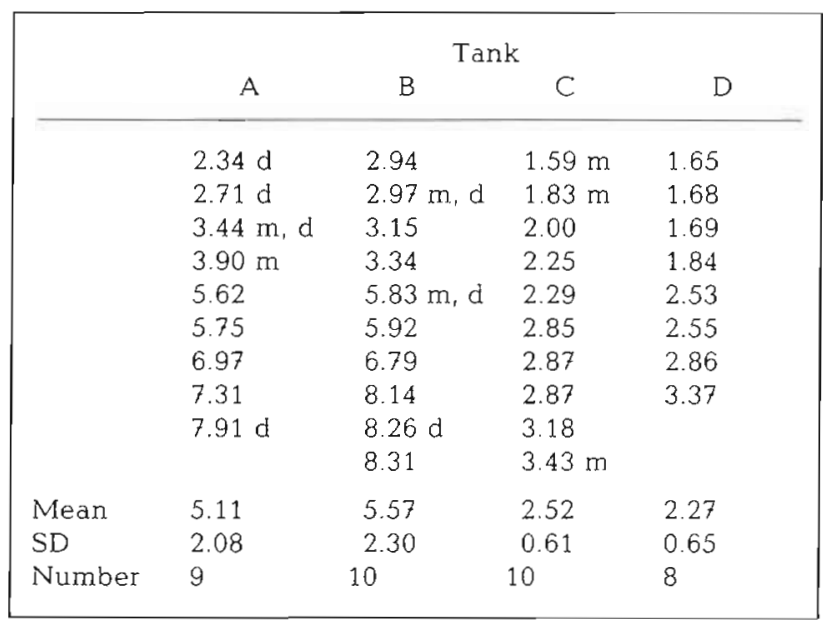

Table 5. Palaemon elegans. Rates of labelled zinc loss $\left(\mu \mathrm{g} \mathrm{g}^{-1}\right.$ $\mathrm{d}^{-1}$ ) by individual prawns in $A_{1}(25 \%$ isosmotic to $75 \%$ SW) $\mathrm{B}_{1}(25 \% \mathrm{SW}): \mathrm{C}_{1}(75 \% \mathrm{SW}): \mathrm{D}_{1}(25 \% \mathrm{SW})$; following uptake in $75 \% \mathrm{SW}$, with $10.6 \mathrm{\mu g} \mathrm{\textrm {l } ^ { - 1 }}$ unlabelled zinc following $7 \mathrm{~d}$ uptake in $120 \mu \mathrm{g} \mathrm{I}^{-1}$ of labelled zinc, at $10^{\circ} \mathrm{C} . \mathrm{m}=$ prawn subsequently moulted, $\mathrm{d}=$ prawn subsequently died

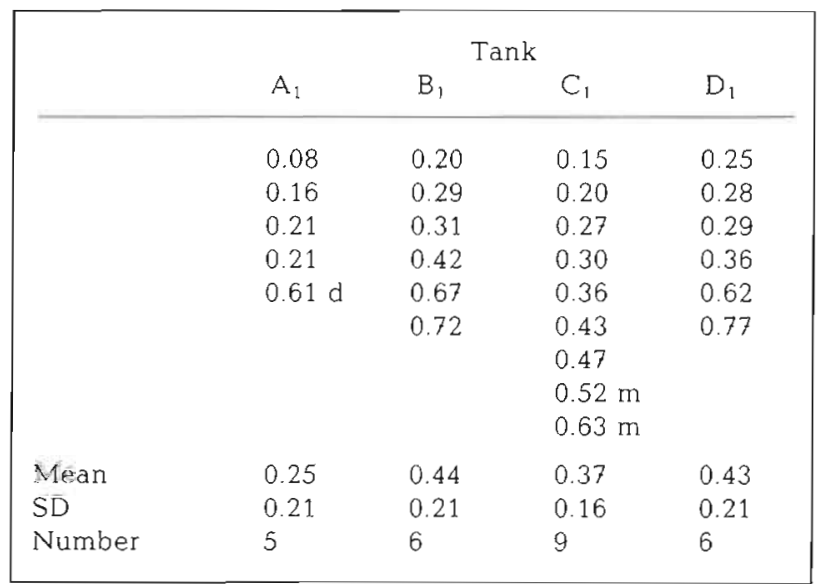


again showed no significant difference between any of the 4 mean rates of loss of labelled zinc, again perhaps as a result of the few data points and high variability.

\section{DISCUSSION}

It is known that Palaemon elegans regulates the body concentration of zinc to a constant level by balancing zinc excretion to match the rate of zinc uptake, which varies with exposure zinc concentration and changing physicochemical features of the medium (White \& Rainbow 1982, 1984a,b, Nugegoda \& Rainbow 1987, 1988, 1989). At a threshold of zinc bioavailability, the rate of zinc uptake exceeds the maximum rate of zinc excretion possible under the ambient physicochemical conditions and net accumulation of body zinc begins, i.e. regulation breaks down. The rate of zinc uptake by $P$. elegans increases with decrease in salinity over the range $100 \% \mathrm{SW}$ to $25 \% \mathrm{SW}$, and there is a corresponding decrease in the exposed zinc concentration at the point of regulation breakdown, but only over the range $100 \%$ SW to $50 \%$ SW (Nugegoda \& Rainbow 1989). In $25 \%$ SW the typical pattern of body zinc regulation and regulation breakdown shown by $P$, elegans over a series of dissolved zinc exposures is lacking (Nugegoda \& Rainbow 1989). A high osmotic throughput and consequently high efflux of salts would be expected for $P$. elegans at $25 \%$ SW, and it is possible that this osmotic throughput causes an atypically high efflux of zinc thereby preventing regulation breakdown (Nugegoda \& Rainbow 1989).

Both experiments showed that uptake of zinc by Palaemon elegans is independent of changes in osmolality when salinity is kept constant. As expected, uptake rates of zinc by $P$. elegans were higher in the higher zinc exposure, all other physicochemical characteristics being constant.

The uptake and consequent loss of labelled zinc were followed in individual prawns. In Experiment 1, the labelled zinc accumulated appeared to asymptote after ca $3 \mathrm{~d}$ and then increased further. This pattern of accumulation can be interpreted after White \& Rainbow (1984a) and Nugegoda \& Rainbow (1989), i.e. the body zinc consists of at least 2 pools: a rapidly exchanging (fast) pool and slower pool(s) filling more slowly. The apparent asymptote of accumulated labelled zinc in the bodies of prawns after $3 \mathrm{~d}$ exposure to $316 \mu \mathrm{g} \mathrm{Zn}$ $1^{-1}$ at $25 \% \mathrm{SW}$ (whether or not isosmotic to $75 \% \mathrm{SW}$ ) at $10^{\circ} \mathrm{C}$ is interpreted to be a result of the filling of the fast pool (see Fig. 6). The initial rate of accumulation of labelled zinc over the first $3 \mathrm{~d}$ period is therefore a
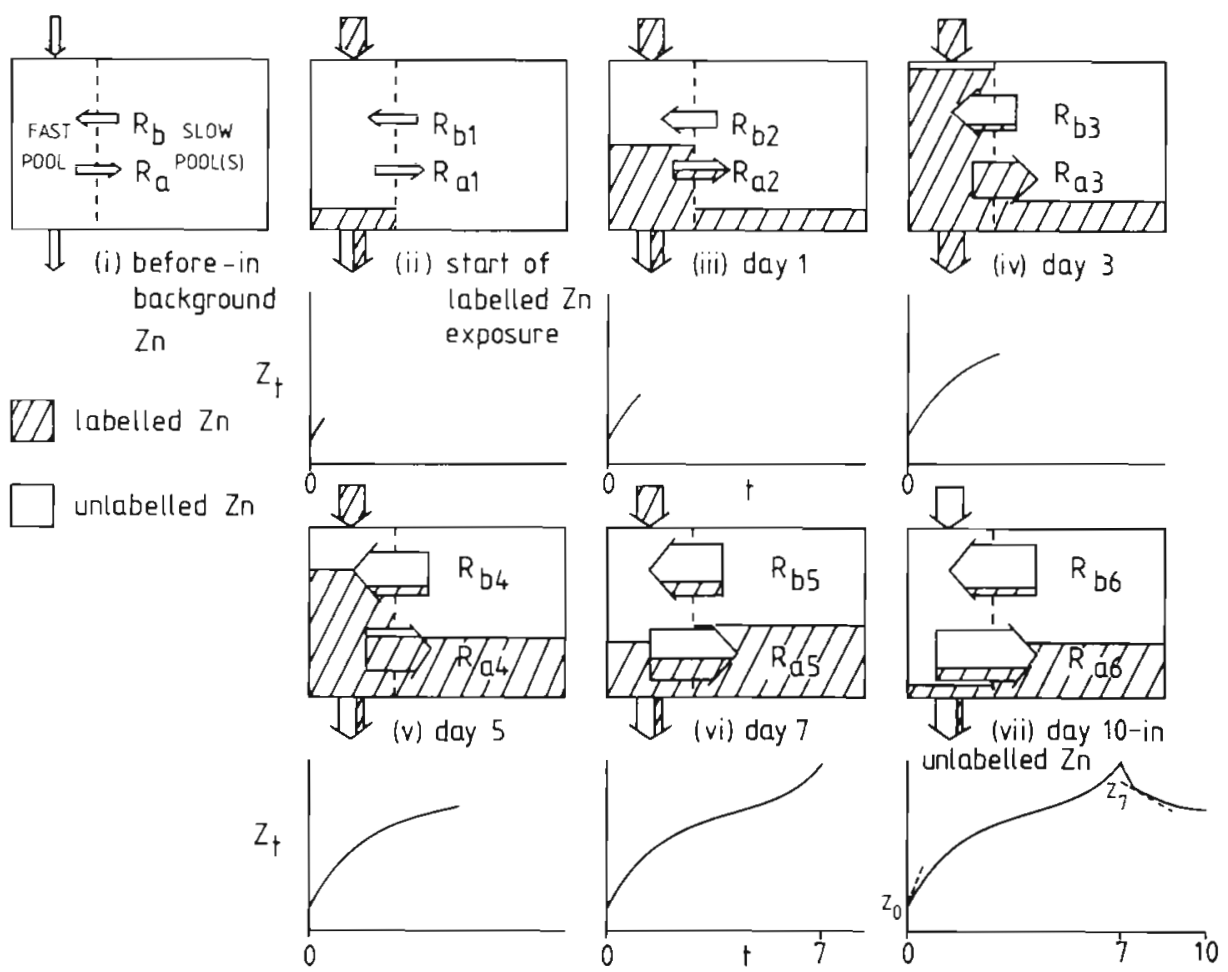

Fig. 6. Palaemon elegans. Possible model of uptake and loss of labelled and unlabelled zinc from an individual prawn in $316 \mu \mathrm{g} 1^{-1}$ labelled zinc for $7 \mathrm{~d}$, followed by $14 \mathrm{~d}$ exposure to $316 \mu \mathrm{g} \mathrm{l}_{-1}$ unlabelled zinc, in $25 \% \mathrm{SW}$ at $10^{\circ} \mathrm{C}$. It is assumed that the zinc within the prawns consists of 2 or more pools which exchange with each other and the environment at proportionally different rates. (No significance of exact representation of size of compartments and proportional rates is intended). $R=$ rate of exchange of zinc between pools; $Z_{1}=$ labelled zinc concentration in prawn $\left(\mathrm{ug} \mathrm{g}^{-1}\right)$ at time $\mathrm{t}$ (days) 
measure of the uptake of total zinc, after allowance for initial adsorption of labelled zinc onto the surface of the prawns (Nugegoda \& Rainbow 1988). In Experiment 2. the filling of the fast pool of zinc has taken $7 \mathrm{~d}$ as a result of the lower rate of zinc uptake at the lower exposure of $120 \mathrm{ug} \mathrm{Zn} \mathrm{l}^{-1}$ (see White \& Rainbow 1984a, Nugegoda \& Rainbow 1989).

When the body concentration of zinc is regulated (as in the case of prawns exposed to $316 \mu \mathrm{gn} \mathrm{I}^{-1}$ in $25 \%$ SW in Experiment 1 and in all zinc exposures in Experiment 2), the rate of zinc excretion matches the rate of zinc uptake. On transfer of the prawns into unlabelled zinc, at the same concentration and under the same physicochemical conditions, excreted zinc will consist of both labelled and unlabelled zinc portions (see Fig. 6). It is not surprising therefore that the measured rate of excretion of labelled (as opposed to total) zinc is less than the rate of uptake of labelled (equivalent to total) zinc in prawns exposed to high zinc in $25 \% \mathrm{SW}$ in both experiments.

With the proviso that the measured rate of loss of labelled zinc is not a measure of the loss of total zinc, both experiments do suggest that for given physicochemical conditions the rate of zinc excretion by Palaemon elegans may be greater in low osmolality whilst uptake rates are equal (see Tables 1 and 2, for Experiment 1; Tables 4, Tanks $A$ and $B$, and 5, Tanks $A_{1}$ and $B_{1}$, for Experiment 2). This indication (needing statistical verification with more data points) is in line with the potential role of high osmotic throughput of water promoting zinc excretion. On the other hand in Experiment 2, transfer of prawns into the low osmolality of $25 \% \mathrm{SW}$ did not appear to promote the loss of labelled zinc taken up in $75 \%$ SW (Tanks C and D in Table 4; Tanks $\mathrm{C}_{1}$ and $\mathrm{D}_{1}$ in Table 5).

Small et al. (1973), analysing the flux of zinc through the euphausiid crustacean Meganyctiphanes norvegica, showed that the loss of $\mathrm{Zn}-65$ could be resolved into 3 components. Similarly Miramand et al. (1981) analysed the loss of radioactive vanadium- 48 from Carcinus maenas by resolving the loss curve into 3 compartments. In the present study however the loss of labelled zinc was monitored for a maximum period of $14 \mathrm{~d}$, and there were insufficient data points to resolve the loss of labelled zinc into several components by curve stripping analysis (Shipley \& Clark 1972). Even though zinc loss would necessarily be from several differentially exchanging pools of zinc within the prawn, the data for the loss of labelled zinc could be adequately described by the single exponential equation.

This study has shown that uptake of zinc by the prawn Palaemon elegans is dependent on salinity but not on osmolality of the medium (cf. cadmium and excised gills of the mussel Mytlus edulis; George et al. 1978). The dependence of zinc uptake on the salinity but not the osmolality of the medium may be explained according to the view of Sunda et al. (1978), Engel \& Fowler (1979) and Nugegoda \& Rainbow (1989), that the free metal ion is the most bioavailable for uptake by aquatic organisms. Zinc is complexed by chloride in seawater, but as salinity is reduced the concentration of the free zinc ion is increased while concentrations of zinc-chloro complexes fall (Mantoura et al. 1978). Such changes in inorganic complexation of zinc are independent of changes in osmolality other than those proportional to changes in salinity. The design of the experiments described has not ruled out completely the possibility of a link between calcium uptake (an active process) and zinc uptake, for calcium concentrations in the media will also have varied with salinity (see Wright 1977). Nevertheless palaemonid prawns would only need increased active uptake of calcium when hyperregulating, to make up for the loss of calcium with increased efflux of urine from the antennary glands (Mantel \& Farmer 1983). In this case zinc uptake rates would be expected to be lower in prawns exposed to zinc in $25 \%$ isosmotic to $75 \%$ SW than in prawns exposed to $25 \% \mathrm{SW}$. In this study uptake rates in such comparisons were equal.

Acknowledgements. This work was carried out while D. N was in receipt of a Commonwealth Scholarship (Association of Commonwealth Universities) and P. S. R. was supported by NERC Grant GR3/5256. We are grateful to Mr A. G. Scott for his advice.

\section{LITERATURE CITED}

Engel, D. W., Fowler, B. A. (1979). Factors influencing cadmium accumulation and its toxicity to marine organisms. Environ. Hith Perspectives 28: 81-88

George, S. G., Carpene, E., Coombs, T L. (1978). The effect of salinity on the uptake of cadmium by the common mussel, Mytilus equlus (L.). In: McLusky, D. S., Berry, A. J. (eds.) Physiology and behaviour of marine organisms. Proceedings 12th European Marine Biology Symposium. Pergamon Press, Oxford, p. 189-193

Mantel, L. H., Farmer, L. L. (1983). Osmotic and ionic regulation. In: Mantel, L. H. (ed.) The biology of Crustacea, Vol.5. Internal Anatomy and Physiological Regulation. Academic Press, New York, p. 54-161

Mantoura, R. F. C., Dickson, A., Riley, J. P. (1978). The complexation of metals with humic materials in natural waters. Estuar coast. mar. Sci. 6: 387-408

Miramand, P., Guary, J. C., Fowler, S. W. (1981). Uptake, assimilation and excretion of vanadium in the shrimp Lysmata seticaudata (Risso), and the crab. Carcinus maenas (L.). J. exp. mar. Biol. Ecol. 49: 267-287

Nugegoda, D. Rainbow, P. S. (1987). The effect of temperature on zinc regulation by the decapod crustacean Palaemon elegans. Ophelia 27: 17-30

Nugegoda, D., Raimbow, P. S. (1988). Effect of a chelating agent (EDTA) on zinc uptake and regulation by Palaemon elegans (Crustacea: Decapoda). J. mar biol. Ass. U. K. 68: $25-40$ 
Nugegoda, D., Rainbow, P. S. (1989). Effects of salinity changes on zinc uptake and regulation by the decapod crustaceans Palaemon elegans and Palaemonetes varians. Mar Ecol. Prog. Ser. 51. 57-75

Panikkar, N. K. (1941). Osmoregulation in some palaemonid prawns. J. mar biol. Ass. U. K. 25: 317-359

Parry, G. (1955). Urine production by the antennal glands of Palaemonetes varians (Leach). J. exp. Biol. 32: 408-422

Ramirez de Isla Hernandez, S., Taylor, A. C. (1985). The effect of temperature on osmotic and ionic regulation in the prawn, Palaemon elegans (Rathke). Ophelia 24: 1-15

Shipley, R. A., Clark, R. L. (1972). Tracer methods for in vivo kinetics. Academic Press, New York

Small, L. F., Fowler, S. W., Keckes, S. (1973). Flux of zinc through a macroplanktonic crustacean. In: Anon. (ed.) Radioactive contamination of the marine environment. Int. Atomic Energy Agency, Vienna, p. 437-452

Sokal, R. R., Rohlf, F. J. (1981). Biometry, 2nd edn. W. H. Freeman \& Co., San Francisco

Sunda, W. G., Engel, D. W., Thuotte, R. M. (1978). Effects of

This article was submitted to the editor chemical speciation on toxicity of cadmium to grass shrimp Palaemonetes pugio: importance of free cadmium ion. Environ. Sci. Technol. 12: 409-413

Weast, R. C. (ed.) (1977). CRC handbook of chemistry and physics. A ready reference book of chemical and physical data 1977-1978. 58th edn. CRC Press Inc., Florida

White, S. L., Rainbow, R. S. (1982). Regulation and accumulation of copper, zinc and cadmium by the shrimp Palaemon elegans. Mar Ecol. Prog. Ser. 8: 95-101

White, S. L., Rainbow, P. S. (1984a). Regulation of zinc concentration by Palaemon elegans (Crustacea : Decapoda): zinc flux and effects of tempreature, zinc concentration and moulting. Mar. Ecol. Prog. Ser 16: 135-147

White, S. L., Rainbow, P. S. (1984b). Zinc flux in Palaemon elegans (Crustacea : Decapoda): moulting, individual variation and tissue distribution. Mar. Ecol. Prog. Ser 19: 153-166

Wright, D. A. (1977). The effect of calcium on cadmium uptake by the shore crab Carcinus maenas. J. exp. Biol. 67 : 163-173

Manuscript first received: November 16, 1988

Revised version accepted: April 29, 1989 